\title{
Thermal Studies and Analytical Applications of a Newly Synthesized Composite Material "Polyaniline Stannic Molybdate"
}

\author{
Sajad Ahmad Ganai ${ }^{1 *}$, Javid Ahmad Banday ${ }^{1}$, Abid Hussain Shalla ${ }^{2}$, Tabassum Ara ${ }^{1}$ \\ ${ }^{1}$ Department of Chemistry, National Institute of Technology, Srinagar, Kashmir \\ ${ }^{2}$ Islamic University of Science and Technology, Awantipora, India \\ Email: *sajadali16@gmail.com
}

Received December 3, 2012; revised January 4, 2013; accepted January 14, 2013

Copyright (C) 2013 Sajad Ahmad Ganai et al. This is an open access article distributed under the Creative Commons Attribution License, which permits unrestricted use, distribution, and reproduction in any medium, provided the original work is properly cited.

\begin{abstract}
Polyaniline stannic molybdate-an organic-inorganic composite material, was prepared via sol-gel mixing of organic polymer polyaniline into matrices of inorganic precipitate of stannicmolybdate. The composite material synthesized at $\mathrm{pH} 1.2$ showed an ion exchange capacity $1.8 \mathrm{meq} / \mathrm{g}$ for $\mathrm{Na}^{+}$ions. Ion exchange capacity, $\mathrm{pH}$ titration and distribution studies were carried out to determine the preliminary ion exchange properties of the material. The distribution studies showed the selectivity of $\mathrm{Hg}(\mathrm{II})$ ions by this material. The effect of temperature on the ion exchange capacity of the material at different temperatures had been studied. The sorption behavior of metal ions was also explored in different surfactant media.
\end{abstract}

Keywords: Organic-Inorganic Hybrid Material; Polyaniline Stannic Molybdate; Synthesis; Thermal Studies

\section{Introduction}

Ion exchangers are always of large scale interest because of their higher selectivity and resistance at higher temperature. These materials have found large scale applications in water treatment and pollution control. An ion exchanger may be organic, inorganic or hybrid depending upon the nature of matrix of which it is made up of. Out of these, hybrid ion exchangers have received more attention because both organic as well as inorganic ion exchangers have some limitations. Organic ion exchangers are very sensitive to exposure to high radiation doses, which cause significant changes in their capacity and selectivity, presumably through hydrolysis of their functional groups, chain scission, and changes in their crosslinking. The inorganic ion exchangers have several superior qualities required for the treatment of industrial waste effluents compared to organic resins. In order to obtain a combination of these advantages associated with polymeric and inorganic materials as ion-exchangers, attempts have been made to develop polymeric-inorganic composite ion-exchangersby incorporation of inorganic monomers in the organic matrix. A composite ion-ex-

\footnotetext{
"Corresponding author.
}

changer must be an interesting material, as it should possess the mechanical stability due to the presence of organic polymeric species and the basic characteristics of an inorganic ion-exchanger regarding its selectivity for some particular metal ions [1]. It was therefore considered to synthesize such hybrid ion-exchangers with a good ion-exchange capacity, high stability, reproducibility and selectivity for metal ions [2,3], indicating its useful environmental applications.

The work deals with the synthesis, ion exchange properties and thermal stability of polyaniline stannic molybdate, prepared by the incorporation of conducting polymer, i.e. polyanniline into the matrices of inorganic ion exchanger stannic molybdate.

\section{Experimental}

\subsection{Reagents and Instruments}

The main reagents used for the synthesis were aniline, stannic chloride pentahydrate and potassium persulphate (LobaChemePvt Ltd (India). All other chemicals and reagents used were of analytical grade. The main instruments used during the study were UV-vis spectrophotometer (Elico EI 301E, India), a PW 1148/89 based 
X-ray diffractometer (Phillips, Holland), a water bath incubator shaker (MSW-275, India) and muffle furnace (G1-111, India).

\subsection{Preparation of Reagent}

The solutions of $0.1 \mathrm{M}$ Stannic chloride pentahydrate were prepared in demineralized water (DMW) and solutions of $10 \%(\mathrm{v} / \mathrm{v})$ of double distilled aniline and $0.1 \mathrm{M}$ potassium persulphate were prepared in $1.0 \mathrm{M} \mathrm{HCl}$.

\subsection{Preparation of Polyaniline Stannic Silicate}

Polyaniline gels were prepared by mixing different volume ratio of $10 \%$ aniline and $0.1 \mathrm{M}$ potassium persulphate with continuous stirring by a magnetic stirrer (Table 1). Green colored polyaniline gels were obtained by keeping the solution below $10^{\circ} \mathrm{C}$ for half an hour [4]. A precipitate of stannic (IV) molybdate was prepared at room temperature $\left(25^{\circ} \mathrm{C} \pm 2^{\circ} \mathrm{C}\right)$ by adding mixture of 0.1 $\mathrm{M}$ sodium molybdate solution gradually to an aqueous solution of $0.1 \mathrm{M}$ stannic chloride pentahydrate in different volume ratios. The white precipitates were obtained. The desired $\mathrm{pH}$ of the mixture was adjusted by adding $\mathrm{HCl}$ with continuous stirring. The gels of polyaniline were then added to the white inorganic precipitate of stannic(IV) molybdate and mixed thoroughly with constant stirring [5-7]. The resultant green color gels so obtained were kept for $24 \mathrm{~h}$ at room temperature $\left(25^{\circ} \mathrm{C} \pm\right.$ $2^{\circ} \mathrm{C}$ ) for digestion. The supernatant liquid was filtered off by suction. The gel was washed with demineralized water (DMW) till the filtrate was neutral. The product was dried in an oven at $50^{\circ} \mathrm{C}$. The dried material was broken into small granules on immersion in DMW. The granules were converted into $\mathrm{H}^{+}$form by placing in $1 \mathrm{M} \mathrm{HNO}_{3}$ solution for $24 \mathrm{~h}$. The excess acid from the material was removed after several washings with DMW and finally dried at $50^{\circ} \mathrm{C} \pm 2{ }^{\circ} \mathrm{C}$. In this way a number of samples of polyaniline stannic molybdate were prepared in different experimental conditions described in Table 1. It was decided to study sample S-9 in detail on the basis of highest ion exchange capacity for $\mathrm{Na}^{+}$ions.

\subsection{Column Ion-Exchange Capacity}

To determine the ion-exchange capacity, column process was used. $1.0 \mathrm{~g}$ dry cation-exchanger in $\mathrm{H}^{+}$form was packed in a column $(1.0 \mathrm{~cm}$ id) fitted with glass wool at the bottom. Metal nitrates as eluents were used to elute the $\mathrm{H}^{+}$ions completely from the cation-exchanger column. The effluent was titrated against a standard solution of $0.1 \mathrm{M} \mathrm{NaOH}$.

\subsection{Thermal Stability}

In order to determine the effect of heating temperature on ion-exchange capacity, 1.0 g sample of the material (S-9) in $\mathrm{H}^{+}$form was heated at different temperatures in a muffle furnace for $1 \mathrm{~h}$ and $\mathrm{Na}^{+}$ion-exchange capacity was determined by standard column process as mentioned above.

\subsection{Distribution Studies}

The distribution coefficients (Kd) for various metal ions were determined in different concentrations of surfactant

Table 1. Synthesis of polyaniline stannic molybdate in different conditions.

\begin{tabular}{|c|c|c|c|c|c|c|c|}
\hline \multirow[t]{2}{*}{ Sample } & \multicolumn{4}{|c|}{ Mixing volume ratio } & \multirow[t]{2}{*}{$\begin{array}{l}\mathrm{pH} \text { of the mother liqor with } \\
\text { inorganic precipitate }\end{array}$} & \multirow[t]{2}{*}{$\begin{array}{c}\text { Sodium ion exchange } \\
\text { capacity (meq/g) }\end{array}$} & \multirow[t]{2}{*}{$\begin{array}{l}\text { Appearance of beads } \\
\text { after drying at } 50^{\circ} \mathrm{C}\end{array}$} \\
\hline & A & B & $\mathrm{C}$ & $\mathrm{D}$ & & & \\
\hline $\mathrm{S} 1$ & 1 & 1 & 1.0 & 1.0 & 0.5 & 0.37 & Green \\
\hline $\mathrm{S} 2$ & 2.0 & 2.0 & 1.0 & 1.0 & 0.5 & 0.6 & Green \\
\hline S3 & 1.0 & 2.0 & 1.0 & 1.0 & 0.5 & 0.85 & Green \\
\hline S4 & 1.0 & 2.0 & 1.0 & 1.0 & 0.5 & 0.7 & Dirty White \\
\hline S5 & 1.0 & 2.0 & 1.0 & 1.0 & 0.7 & 0.74 & Dark Green \\
\hline S6 & 1.0 & 2.0 & 1.0 & 1.0 & 0.8 & 0.90 & Dark Green \\
\hline S7 & 1.0 & 2.0 & 1.0 & 1.0 & 0.9 & 1.44 & Dark Green \\
\hline S8 & 1.0 & 2.0 & 1.0 & 1.0 & 1.0 & 1.62 & Dark Green \\
\hline S9 & 1.0 & 2.0 & 1.0 & 1.0 & 1.2 & 1.8 & Dark Green \\
\hline $\mathrm{S} 10$ & 1.0 & 2.0 & 1.0 & 1.0 & 1.4 & 1.5 & Dark Green \\
\hline S11 & 1.0 & 2.0 & 1.0 & 1.0 & 1.6 & 1.4 & Dark Green \\
\hline
\end{tabular}

A: 0.1M Stannic chloride pentahydrate; B: 0.1M sodium molybdate; C: $10 \%$ Aniline in 1.0M HCl; D: $0.1 \mathrm{M} \mathrm{K2S2O8} \mathrm{in} \mathrm{1.0M} \mathrm{HCl.}$ 
(SDS).The effect of temperature on the distribution coefficient was also studied. Polyaniline stannic molybdate $(0.3 \mathrm{~g})$ in $\mathrm{H}^{+}$form was put into $100 \mathrm{ml}$ conical flasks each containing $30 \mathrm{~mL}$ solution of $0.1 \mathrm{M}$ concentration of metal ions. The mixture was continuously shaken for a definite period of time at $30^{\circ} \mathrm{C}, 45^{\circ} \mathrm{C}, 60^{\circ} \mathrm{C}$ and $75^{\circ} \mathrm{C}$ (Table 2). The amount of metal ions present in the solution was determined by titrating it against disodium salt of EDTA (0.01 M) using standard procedures.

\section{Results and Discussion}

In this study of preparation and characterization of organic-inorganic composite cation exchange material, a number of samples of organic-inorganic electrically conducting composite stannicmolybdate providing a new class of hybrid ion-exchangers were prepared by sol-gel mixing of organic conducting polymer, polyaniline with the inorganic precipitate of stannic molybdate (Table 1). Among them, sample S-9 possessed enhanced $\mathrm{Na}^{+}$ion exchange capacity $(1.8 \mathrm{meq} / \mathrm{g})$ and better thermal stability. Polyaniline gel was prepared by oxidation coupling using $\mathrm{K}_{2} \mathrm{~S}_{2} \mathrm{O}_{8}$ in acidic aqueous medium.

The effect of temperature on the reaction seems to be very pronounced. Aniline underwent oxidation coupling only below $10^{\circ} \mathrm{C}$ very effectively, leading to formation of polyaniline with fairly good yield.

However sample S9 of polyaniline stannic molybdate exhibited better granulometric and mechanical properties and reproducible behavior as is evident from Table 1. The samples prepared in various batches did not show any appreciable deviation in their ion exchange capacities. The ion exchange capacity of the composite cation exchanger for alkali metal ions and alkaline earth metal ions increases according to the increase in the hydrated ionic radius increases (Table 3). It was observed that on heating the material at different temperatures, ion exchange capacity of the dried sample material (S9) was changed as the temperature increased as shown in Table 4. From the comparative study of $\mathrm{Na}^{+}$ion exchange capacity of polyaniline stannic molybdate with those of other ion exchangers, as shown in Table 5, it is apparent that this composite cation exchanger has more ion exchange capacity than others.

Table 2. Effect of temperature on theKd $\left(\mathrm{mL} \cdot \mathrm{g}^{-1}\right)$ of metal ions in $0.1 \mathrm{M}$ SDS.

\begin{tabular}{ccccc}
\hline \multirow{2}{*}{ Metal ions } & \multicolumn{4}{c}{ Temperature $\left({ }^{\circ} \mathrm{C}\right)$} \\
\cline { 2 - 5 } & 30 & 45 & 60 & 70 \\
\hline $\mathrm{Mg}^{2+}$ & 18 & 15 & 11 & 4 \\
$\mathrm{Cd}^{2+}$ & 11 & 19 & 13 & 8 \\
$\mathrm{Zn}^{2+}$ & 35 & 49 & 31 & 19 \\
$\mathrm{Mn}$ & 27 & 35 & 24 & 22 \\
\hline
\end{tabular}

Table 3. Ion exchange capacity of polyaniline stannic molybdate (sample S-9) for different metal ions.

\begin{tabular}{cccc}
\hline Exchanging ions & Ionic radii $\left(\mathrm{A}^{\circ}\right)$ & $\begin{array}{c}\text { Hydrated ionic } \\
\text { radii }\left(\mathrm{A}^{\circ}\right)\end{array}$ & $\begin{array}{c}\text { Ion exchange } \\
\text { capacity (meq/g) }\end{array}$ \\
\hline $\mathrm{Na}^{+}$ & 0.97 & 2.76 & 1.8 \\
$\mathrm{~K}^{+}$ & 1.33 & 2.32 & 1.3 \\
$\mathrm{Mg}^{2+}$ & 0.78 & 7.00 & 1.2 \\
$\mathrm{Ba}^{2+}$ & 1.43 & 5.90 & 0.9 \\
\hline
\end{tabular}

Table 4. Effect of temperature on the ion-exchange capacity of polyaniline stannic molybdate.

\begin{tabular}{ccc}
\hline Temperature ${ }^{\circ} \mathrm{C}$ & color & $\begin{array}{c}\text { Retention of ion } \\
\text { exchange capacity (\%) }\end{array}$ \\
\hline 50 & Green & 100 \\
100 & Green & 94 \\
200 & Green & 78 \\
300 & Light green & 63 \\
400 & Brown & 52 \\
500 & White & 41 \\
600 & white & 35 \\
\hline
\end{tabular}

Table 5. Comparison of ion exchange capacity of polyaniline stannic molybdate with those of other cation exchangers.

\begin{tabular}{cc}
\hline Ion exchange material & $\mathrm{Na}^{+}$exchange capacity \\
\hline Polyanilinesn(II) arsenophosphate [6] & 1.58 \\
PolyanilineSn(II) tungstate [7] & 0.75 \\
PolyanilineSn(II)arsenate [8] & 0.87 \\
PolyanilineSn(II) tungstoarsenate [9] & 1.67 \\
Sn(IV) tungstoarsenate [7] & 1.06 \\
PolyanilineZr(IV) tungstophosphate [10] & 1.46 \\
PolyanilineSn(II) molybdate & 1.8 \\
\hline
\end{tabular}

In order to explore the potentiality of polyaniline stannic molybdate in separation of metal ions, distribution studies of some metal ions were achieved in various concentrations of SDS. It is apparent from the data in Tables 2 and $\mathbf{6}$ that the Kd values varied with temperature and conc. of contacting solvents. The $\mathrm{Kd}$ values of metal ions increases up to $45^{\circ} \mathrm{C}$ and then decreases, Thus $45^{\circ} \mathrm{C}$ is the optimum temperature for the $\mathrm{Kd}$ value determination. It was also observed from kd values that the $\mathrm{Hg}(\mathrm{II})$ was highly adsorbed in all solvents while remaining metal ions were poorly adsorbed. The high uptake of $\mathrm{Hg}$ (II) in all solvents demonstrate not only the ion exchange properties but all the adsorption and ion selective 
characterization of the material. The utility of this compound has been demonstrated by achieving some binary separations $\left(\mathrm{Mg}^{2+}-\mathrm{Hg}^{2+}, \mathrm{Cd}^{2+}-\mathrm{Hg}^{2+}\right.$ and $\left.\mathrm{Mn}^{2+}-\mathrm{Hg}^{2+}\right)$ of metal ions on its column. The separations were found to be quantitative and the results obtainedwere quite precise and accurate as is evident from Table 7. $\mathrm{Hg}^{2+}$ has also been selectively separated from a synthetic mixture of metal ions. The salient features of selective separation are summarized in Table 8. Thus we can say that this composite material is highly selective for $\mathrm{Hg}$ (II) and can be used for the separation of mercury from waste effluxents.

\section{Conclusion}

PolyanilineSn(IV) molybdate, an organic-inorganic com-

Table 6. The distribution coefficients of metal ions in SDS $\left(\mathrm{KdmLg}^{-1}\right.$ ) at $30^{\circ} \mathrm{C} \pm 2^{\circ} \mathrm{C}$.

\begin{tabular}{cccccc}
\hline \multirow{2}{*}{ Metal ions s } & \multicolumn{5}{c}{ SDS (Surfactant) } \\
\cline { 2 - 6 } & $0.1 \mathrm{M}$ & $0.01 \mathrm{M}$ & $0.001 \mathrm{M}$ & $0.0001 \mathrm{M}$ & $0.00001 \mathrm{M}$ \\
\hline $\mathrm{Mg}^{2+}$ & 8 & 15 & 17 & 31 & 29 \\
$\mathrm{Cd}^{2+}$ & 11 & 25 & 29 & 34 & 28 \\
$\mathrm{Hg}^{2+}$ & 137 & 145 & 152 & 159 & 143 \\
$\mathrm{Zn}^{2+}$ & 35 & 37 & 45 & 52 & 33 \\
$\mathrm{Mn}^{2+}$ & 27 & 32 & 53 & 66 & 62 \\
\hline
\end{tabular}

Table 7. Quantitative Separations of metal ions in binary mixtures on a column of polyaniline stannic molybdate.

\begin{tabular}{cccccc}
\hline $\begin{array}{c}\text { Separation } \\
\text { achieved }\end{array}$ & $\begin{array}{c}\text { Amount } \\
\text { loaded, } \\
\mathrm{mL}\end{array}$ & $\begin{array}{c}\text { Amount } \\
\text { found, } \\
\mathrm{mL}\end{array}$ & $\begin{array}{c}\text { Recovery } \\
\%\end{array}$ & Eluent used & $\begin{array}{c}\text { Volume } \\
\text { of eluent, } \\
\mathrm{mL}\end{array}$ \\
\hline $\mathrm{Mg}^{2+}$ & 2.42 & 2.36 & 97.40 & $0.1 \mathrm{M}$ SDS & 70.00 \\
$\mathrm{Hg}^{2+}$ & 20.05 & 20.05 & 100.00 & $0.00001 \mathrm{M}$ SDS & 100.00 \\
$\mathrm{Cd}^{2+}$ & 11.24 & 11.21 & 99.73 & $0.1 \mathrm{M}$ SDS & 90.00 \\
$\mathrm{Hg}^{2+}$ & 20.05 & 19.10 & 95.26 & $0.00001 \mathrm{M}$ SDS & 110.00 \\
$\mathrm{Mn}^{2+}$ & 5.49 & 5.37 & 97.81 & $0.1 \mathrm{M}$ SDS & 80.00 \\
$\mathrm{Hg}^{2+}$ & 20.05 & 19.98 & 99.65 & $0.00001 \mathrm{M}$ SDS & 90.00 \\
\hline
\end{tabular}

Table 8. Selective separation of $\mathrm{Hg}^{2+}$ from a synthetic mixture oh $\mathrm{Hg}^{2+}, \mathrm{Cd}^{2+}, \mathrm{Mn}^{2+}$ and $\mathrm{Mg}^{2+}$ on a column of polyaniline stannic molybdate.

\begin{tabular}{cccc}
\hline $\begin{array}{c}\text { Amount loaded, Amount found, } \\
\mathrm{mg}\end{array}$ & $\begin{array}{c}\% \\
\mathrm{mg}\end{array}$ & $\begin{array}{c}\text { Volume (mL) of } \\
\text { R.00001M SDS used } \\
\text { for complete elution } \\
\text { of } \mathrm{Hg}^{2+} \mathrm{mL}\end{array}$ \\
\hline 2.50 & 2.39 & 95.6 & 110 \\
5.0 & 4.9 & 98.0 & 130 \\
\hline
\end{tabular}

posite cation exchange material represents a new class of ion exchange materials that combines good characteristics of both organic and inorganic components within a single composite. It is quite clear from the results that the composite cation exchanger has enhanced ion exchange capacity and thermal stabilities. The selective behavior of polyanilineSn(II) molybdate is important from environmental pollution chemistry point of view, where an effective separation method is needed for the removal of Hg(II) ions.

\section{Acknowledgements}

The authors are highly thankful to the H.O.D. Chemistry (Dr. S. A. Shah) and Director, National Institute of Technology (NIT) Hazratbal, Srinagar for providing the research facilities.

\section{REFERENCES}

[1] K. G. Varshney, N. Tyal and U. Gupta, “Acrylonitrile Based Cerium (IV) Phosphste as a New Mercury Selective Fibrous Ion-Exchanger: Synthesis, Characterization and Analytical Applications," Colloidal and Surfaces A, Vol. 145, No. 2-3, 1998, pp. 71-81.

[2] H. Zhang, J. H. Pang, D. Wang and Z. Jiang, "Sulphonated Poly(acryleneether nitrile ketone) and Its Composite with Phosphotungstic Acid as Materials for Proton Exchange,” Journal of Membrane Science, Vol. 264, No. 1-2, 2005, pp. 56-64.

[3] W. A. Siddiqui and S. A. Khan, "Synthesis, Characterization and Ion Exchange Properties of a New and Novel Organic-Inorganichybridcation Exchanger: Poly(methyl methacrylate) Zr(IV) Phosphate," Colloids and Surfaces A: Physicochemical and Engineering Aspects, Vol. 295, No. 1-3, 2007, pp. 193-219. doi:10.1016/j.colsurfa.2006.08.053

[4] I. M. El-Naggar, E. S. Zakaria, I. M. Ali and M. Khalil, Chemical Studies on Synthetic Polyaniline Titanotungstate and Its Uses to Reduce Cesium from Solutions and Polluted Milk,” Journal of Environmental Radioactivity, No. 112 , 2012, pp. 108-117.

[5] A. A. Khan and Inamuddin, "Applications of Hg(II) Sensitive Polyaniline Sn(IV) Phosphate Compositecation Exchange Material in Determination of $\mathrm{Hg}^{2+}$ from Aqueous Solutions and in Making Ion Selective Membraneelectrode," Sensors and Activators B, Vol. 120, No. 1, 2006, pp. 10-18. doi:10.1016/j.snb.2006.01.033

[6] R. Niwas, A. A. Khan and K. G. Varshney, "Synthesis and Ion Exchange Behaviour of Polyaniline Sn(IV) Arsenophosphate: A Polymeric Ion Exchanger,” Colloids and Surfaces, Vol. 150, 1999, pp. 7-14

[7] A. A. Khan and M. M. Alam, "Synthesis, Characterization and Analytical Applications of a New and Novel Organic-Inorganic Composite Material as Acation Exchanger and Cd(II) Ion-Selective Membrane Electrode: Polyaniline Sn(IV) Tungstoarsente," Journal of Reactive and Functional Polymers, Vol. 55, No. 3, 2003, pp. 277-290. doi:10.1016/S1381-5148(03)00018-X 